\title{
Impactos da reestruturação organizacional na saúde dos motoristas de ambulância em um hospital universitário
}

\author{
Impacts of organizational restructuring on the health of ambulance \\ drivers from a university hospital
}

Daniele Pimentel Maciel (https://orcid.org/0000-0002-5034-3349) ${ }^{1}$

Ruri Giannini (https://orcid.org/0000-0003-4340-7516) ${ }^{1}$

Eduardo Costa Sá (https://orcid.org/0000-0001-6431-5421) ${ }^{2}$

Laerte Idal Sznelwar (https://orcid.org/0000-0001-7703-0476) ${ }^{1}$

${ }^{1}$ Programa de PósGraduação em Engenharia de Produção, Escola Politécnica, Universidade de São Paulo. daniele. maciel23@gmail.com ${ }^{2}$ Faculdade de Medicina, Universidade de São Paulo. São Paulo SP Brasil.

\begin{abstract}
The transport of patients by ambulance is part of the services offered by a Hospital and its importance lies in facilitating the connection between the institutes involved in patient care. However, a significant amount of complaints about irritability and aggressiveness of drivers was registered after a strategic change in the organizational structure that directly affected these professionals. This study aimed to survey the health issues of ambulance drivers at this hospital, from the reorganization of work, through an ergonomic analysis of work. The data were obtained through observation and interviews with managers, leaders, and drivers of the transport sector of the hospital. The main results found were: 1) the key performance measurement is time, which is a measure that does not consider all variabilities that occur during transport, 2) prescribed work of drivers only considers the task of driving an ambulance, while their real work includes taking care and paying attention to the needs of the patient and other professionals, 3) after the restructuring and centralization of the transport sector, drivers stopped feeling as part of the team of health professionals and started to feel like a "shared service". Key words Ergonomics, Hospital restructuring, Occupational health, Health services
\end{abstract}

Resumo O transporte de pacientes por ambulância é parte dos serviços oferecidos pelo hospital e sua importância está na facilitação da conexão entre os institutos envolvidos no cuidado do paciente. No entanto, quantidade significativa de reclamações a respeito da irritabilidade e agressividade dos motoristas foi registrada após reestruturação organizacional que afetou diretamente este grupo de profissionais. O objetivo deste estudo foi fazer um levantamento das questões de saúde dos motoristas de ambulância deste hospital, a partir da reorganização do trabalho, por meio de uma análise ergonômica do trabalho. Os dados foram obtidos por meio de observação da situação de trabalho e entrevistas com gerentes, líderes e motoristas do setor de transporte do hospital. Os principais resultados foram: 1) o principal indicador de desempenho é o tempo,que desconsidera as imprevisibilidades que ocorrem nos trajetos; 2) o trabalho prescrito dos motoristas só considera a tarefa de dirigir a ambulância, mas o trabalho real engloba o cuidado e atenção às necessidades do paciente e de outros profissionais; 3) com a reestruturação e centralização do setor, os motoristas deixaram de se sentir parte do time de profissionais de saúde e passaram a se sentir como um "serviço compartilhado".

Palavras-chave Ergonomia, Reestruturação hospitalar, Saúde do trabalhador, Serviços de saúde 


\section{Introdução}

Mudanças organizacionais envolvem uma transformação delimitada temporalmente ${ }^{1}$ e ocorrem desde o nível mais amplo e conceitual (cultura organizacional) ao nível mais restrito e concreto (mudanças de equipamentos ou remanejamento de pessoas $)^{2}$. Entretanto, independentemente do nível, estas mudanças representam uma reestruturação profunda do ambiente da organização, uma vez que há uma reorganização das relações de poder e dos papéis dos diferentes atores sociais.

Apesar dos aspectos positivos na melhoria dos resultados operacionais, mudanças acarretam impacto no conteúdo do trabalho e, consequentemente, possíveis reflexos na saúde dos trabalhadores. Estudos relacionados à saúde do trabalhador em contexto de mudança organizacional têm revelado impactos negativos na saúde, tais como: aumento do absenteísmo, ${ }^{3-6}$ piora da percepção geral da qualidade de saúde, ${ }^{7,8}$ repercussões na saúde mental ${ }^{7,9,10}$ ou demissão voluntária ${ }^{6}$. O impacto sobre a saúde dos trabalhadores é mais significativo nos primeiros anos após a instituição da mudança organizacional, porém os trabalhadores submetidos a longos processos de reestruturação ou a mudanças consecutivas ou repetidas tendem a apresentar efeitos mais duradouros sobre sua saúde mental ${ }^{7}$.

As empresas hospitalares operam em ambiente de constantes mudanças, inclusive organizacionais, em virtude do aumento progressivo dos custos com a saúde, que representa matualmente uma grande parcela dos gastos públicos ${ }^{11}$. Inovações organizacionais no campo da saúde envolvem mudanças relacionadas ao cuidado do paciente ${ }^{11} \mathrm{e}$ mudanças estruturais na organização do hospital, como fusões, incorporações e reestruturações organizacionais. ${ }^{5}$ A reestruturação em serviços públicos de saúde também visa à redução de custos, principalmente estimulados pela disseminação do New Public Management, que incorpora práticas oriundas do setor privado, como terceirizações, privatizações, focos em resultados e não em processos e modalidades padronizadas para medição de desempenho ${ }^{12}$. No Brasil, a adoção dessa estratégia levou a reformas fragmentadas e localizadas, com difusão de "boas práticas" e elevadas doses de experimentalismo, com a ausência de estratégias bem definidas sobre quais as melhores soluções ${ }^{13}$.

Nas operações de serviços do setor de saúde, há trabalhadores diretamente envolvidos com a assistência à saúde (equipe médica e de enfermagem) e outros responsáveis pelo cuidado geral do paciente, como hospitalidade, transporte, alimentação, manutenção e áreas administrativas. Independentemente do grau de envolvimento no cuidado com o paciente, todos os trabalhadores são suscetíveis aos efeitos negativos da reestruturação organizacional ${ }^{4,14}$, porém vivenciam este processo de maneira diferente devido às características particulares do conteúdo do trabalho. $\mathrm{Ou}$ seja, ações de reorganização no conteúdo do trabalho destinadas à redução de condições ansiogênicas ou inadequadas podem produzir reflexos negativos na saúde da equipe de trabalhadores de suporte ao cuidado do paciente ${ }^{14}$.

Grande parte dos estudos que analisaram o sofrimento patogênico relacionado ao trabalho em situação de mudança organizacional prioriza a identificação de estratégias individuais de enfrentamento. Poucos, no entanto, analisam o impacto do contexto compartilhado pelo coletivo de trabalho ou a identificação de questões relacionadas à organização do trabalho na saúde mental dos trabalhadores. Na sua grande maioria, os estudos sugerem que os impactos negativos estariam relacionados à intensificação do trabalho, ao aumento da pressão temporal para a entrega dos resultados, à redução do suporte social e às incertezas relacionadas ao futuro do trabalho, produzindo um ambiente laboral permeado por ambiguidades e incertezas?.

Há escassez de trabalhos na literatura mostrando o impacto da compreensão do trabalho real antes da implantação de uma reestruturação organizacional ${ }^{15}$, ou seja, as mudanças são instituídas sem a compreensão do trabalho real e do seu sentido para aqueles que o realizam. Assim, mudanças organizacionais que reformulam o conteúdo do trabalho sem considerar o seu valor levam à ruptura das regulações coletivas e dos laços de confiança, impactando negativamente na saúde dos trabalhadores pela precarização do trabalho e perda da identidade profissional.

Uma das estratégias de abordagem em análise do trabalho que busca a compreensão do trabalhar sob a perspectiva de seus diferentes determinantes é a ergonomia centrada na atividade ${ }^{16}$. Uma ação ergonômica baseada na compreensão da atividade (Análise Ergonômica do Trabalho AET) procura compreender o trabalhar e as estratégias desenvolvidas pelos trabalhadores para lidar com a discrepância entre trabalho prescrito e trabalho real ${ }^{17}$. Além disso, a partir da AET pode-se compreender como os diferentes aspectos da produção estão inter-relacionados para a constituição dos sistemas e situações de trabalho. Esta compreensão permite a construção de diag- 
nósticos mais profundos e de transformações do trabalho mais abrangentes respeitando as propriedades e limitações humanas.

Já o sofrimento psíquico relacionado ao trabalho envolve uma confluência de aspectos individuais relacionados às estratégias pessoais de enfrentamento, à existência dos coletivos, aos valores profissionais modulados pelo contexto organizacional e pelas mais diferentes modalidades de avaliação de desempenho ${ }^{18}$. Esse sofrimento pode se manifestar clinicamente sob diferentes queixas, e os profissionais envolvidos no atendimento à saúde do trabalhador precisam desenvolver uma escuta ativa para identificar os sinais. Essa situação é agravada quando esses sintomas de sofrimento psíquico se originam em trabalhadores de apoio ao cuidado, uma vez que grande parte dos estudos envolvendo serviços de saúde incluem apenas aqueles envolvidos diretamente com a assistência à saúde, ou seja, não abrangem trabalhadores da limpeza, farmácia hospitalar, manutenção e motoristas de ambulância.

Assim, a principal contribuição deste trabalho para a literatura relacionada à saúde do trabalhador é a discussão da importância da compreensão do trabalho real, utilizando a abordagem da ergonomia da atividade, como referencial metodológico, e conceitos de Psicodinâmica do Trabalho (PDT), como arcabouço teórico, na investigação sobre aspectos envolvidos na saúde mental de motoristas de ambulância de um hospital público.

\section{Método}

Este é um estudo qualitativo com base na análise ergonômica do trabalho (instrumento de compreensão do trabalho real) dos motoristas de ambulância de um Hospital Universitário da cidade de São Paulo. O estudo foi realizado por uma equipe multidisciplinar de pesquisadores, como parte do trabalho de conclusão do curso de pós-graduação (lato sensu em Ergonomia) com supervisão de um dos pesquisadores. Na ocasião, um dos autores do artigo era o coordenador médico no hospital que sugeriu a demanda e atuou como interlocutor facilitador no contato entre os pesquisadores e a equipe de transporte. A demanda para o estudo partiu do Serviço Especializado em Engenharia de Segurança e em Medicina do Trabalho (SESMT) do hospital diante de queixas dos profissionais de enfermagem sobre irritabilidade e agressividade dos motoristas de ambulância, que começou a ocorrer após a reorganização do trabalho no serviço de transporte. Diante das queixas apresentadas, o médico do trabalho coordenador responsável (e coautor deste artigo) encaminhou a solicitação aos pesquisadores, com objetivo de compreender o contexto de trabalho desses profissionais e os possíveis aspectos relacionados à demanda, na tentativa de adotar uma ação mais sistêmica. Nesse sentido, o objetivo do estudo foi fazer um levantamento das questões de saúde dos motoristas de ambulância de um Hospital Universitário em São Paulo, Brasil, a partir da reorganização do trabalho, por meio de uma análise ergonômica do trabalho.

\section{Características do hospital}

O hospital oferece serviços públicos de saúde, além de ser uma instituição de ensino com o objetivo de formar e capacitar profissionais da saúde. Ele é uma autarquia da administração pública, o que significa uma instituição autônoma, descentralizada e com seus próprios recursos, supervisionada pelo Estado. O hospital é composto por diferentes institutos, que oferecem serviços médicos especializados ao público, e cada instituto tem uma gestão descentralizada subordinada à administração central do hospital. O complexo hospitalar ocupa uma área construída de quase $400 \mathrm{mil} \mathrm{m}^{2}$ e o transporte de pacientes por ambulâncias entre institutos é parte dos serviços oferecidos pelo hospital, possibilitando a conexão do paciente entre os institutos especializados que estão envolvidos em seus cuidados.

\section{Setor de transporte}

A contratação dos motoristas de ambulância ocorre exclusivamente por concurso público, cujo edital apresenta requisitos para o exercício do cargo e não há exigência específica quanto à experiência anterior na função. Os trabalhadores aprovados no concurso não recebem capacitação específica para a função e os conhecimentos são passados informalmente pelos trabalhadores mais antigos.

As exigências de qualidade para o setor de transporte estão relacionadas ao tempo dispendido no atendimento, principalmente o tempo máximo de cinco minutos que deve ser cumprido entre o recebimento da chamada e a chegada do motorista no local da remoção. Outra exigência de qualidade está relacionada ao atendimento dos clientes internos da organização e existe uma cobrança quanto à cordialidade no relacionamento com a equipe. 


\section{Características da população}

O setor de transporte era composto por 48 motoristas, todos do sexo masculino. 69\% com mais de 50 anos, ou seja, idade mais avançada, muitos deles próximos da aposentadoria. Além disso, 68\% possuíam ensino médio completo e $79 \%$ estavam a menos de 10 anos na empresa.

\section{Reestruturação organizacional}

O setor de transporte passou por duas reformulações estruturais nos últimos anos. A primeira ocorreu em 2008, quando houve uma descentralização do setor de transportes entre os institutos, e cada instituto recebeu autonomia financeira. Essa opção estratégica acarretou políticas salariais e de benefícios diferenciados entre os motoristas, dependendo do instituto ao qual se encontravam vinculados.

Em 2012, houve uma análise dos resultados da mudança adotada em 2008 e verificou-se que institutos de maior demanda solicitavam o deslocamento dos motoristas de outros institutos, gerando problemas relacionados agestão de pessoas, a política de salários e a questões orçamentárias quanto aos custos com combustível e manutenção das ambulâncias. Desta maneira, implantou-se a estratégia de recentralização do setor de transportes em 2012, com a proposta de uma garagem única, onde todos os motoristas seriam alocados de acordo com a demanda dos institutos.

Para efetivação desse processo foram necessárias reformulações na hierarquia e institui-se o cargo de líder, responsável por centralizar as demandas do plantão regulador e direcionar a saída do motorista. Quem ocupa o cargo de líder é indicado pela chefia imediata, sem um critério bem definido e claro quanto à escolha, e, geralmente, são escolhidos aqueles que apresentam restrições relacionadas à atividade de motorista ou com restrições físicas quanto ao carregamento de peso. $\mathrm{O}$ papel de líder não constitui um cargo dentro da estrutura organizacional da instituição, uma vez que não está inserida no organograma hierárquico. Assim, estes trabalhadores não recebem uma gratificação salarial específica pelo cargo.

\section{Delineamento do estudo}

A metodologia deste estudo está pautada na AET, cujo objeto central é a atividade de trabalho desenvolvida por profissionais em distintas situações de trabalho. A AET é estruturada em diver- sas fases interligadas em um processo interativo e não linear, porque o confronto com o real leva ao retorno a fases anteriores para uma compreensão mais profunda da atividade de trabalho. Portanto, é uma abordagem participativa, adequada à compreensão abrangente do trabalho e à concepção de soluções ${ }^{17}$.

De acordo com Guérin et al. ${ }^{17}$ e Wisner ${ }^{16}$, a AET deve começar com a análise da demanda, para então construir-se o problema, que precisa ser explicitamente expressado. A demanda deste estudo foi a queixa de outros profissionais da saúde, especificamente a equipe de enfermagem, a respeito da irritabilidade e agressividade dos motoristas de ambulância quando eram chamados. Esses profissionais representam a categoria de trabalhadores que interagem com os motoristas de ambulância na dinâmica de trabalho diário, sem constituírem uma hierarquia ou subordinação. Segundo os profissionais da enfermagem, tais reclamações começaram a acontecer após a instauração do processo de reestruturação organizacional de 2012, porém se tornaram de conhecimento do SESMT em 2014.

O estudo foi desenvolvido no período de abril a julho de 2014. Os dois primeiros meses do estudo foram destinados a entrevistas semi -estruturada com gerentes e líderes e à análise documental institucional e dos indicadores de produtividade, para uma compressão geral dos processos de serviços e a relação com outros departamentos do hospital, como objetivo de compreender o funcionamento global da instituição e os determinantes do trabalho dos motoristas de ambulância. Entender o contexto da organização, os fatos que marcaram a história da empresa, os indicadores de produtividade, o volume e conteúdo do trabalho podem revelar elementos que impactam na atividade de trabalho ${ }^{17}$.

A situação de trabalho escolhida e estudada nesta pesquisa foi o transporte de pacientes em ambulâncias de um instituto a outro. Tal escolha foi direcionada pela demanda originada no SESMT do hospital, uma vez que este tipo de transporte requer interação dos motoristas com os pacientes e com os demais profissionais de saúde, além de representar o principal tipo de transporte realizado pelos motoristas. Após a análise global da empresa, entrevistas iniciais e início das observações livres, a demanda inicial foi reformulada no sentido de aprofundar a compreensão dos determinantes do trabalho dos motoristas de ambulância e seus impactos sobre a demanda original.

Ao final dessa primeira fase, foram iniciadas as atividades de campo, com observações livres 
para compreender a dinâmica do trabalho e seus determinantes. O mês de julho de 2014 foi dedicado à realização de observações direcionadas da situação de trabalho específica orientada pela demanda. Foram 40 horas de observação livre e todos os sujeitos de pesquisa foram esclarecidos verbalmente e aceitaram participar voluntariamente da observação livre e da entrevista individual. O objetivo da pesquisa foi explicado pelos pesquisadores antes do início da observação, sendo acordado entre os motoristas aqueles que participariam da observação livre, que envolvia o acompanhamento por um dos pesquisadores no deslocamento entre os institutos. Durante a observação livre foram realizadas entrevistas não estruturadas com os motoristas para a compreensão dos determinantes do trabalho e direcionadas para a compreensão do conteúdo do trabalho.

Foram conduzidas duas entrevistas em grupo com os motoristas ao final de dois períodos diferentes de observação livre. Essas entrevistas coletivas não foram programadas, portanto não estruturadas previamente, e surgiram de maneira orgânica, sendo realizadas espontaneamente na garagem e na sala de recebimento de chamados do líder, com participação voluntária dos motoristas. As entrevistas coletivas incluíram os motoristas que haviam participado da observação livre, bem como aqueles que estavam na garagem após o retorno dos pesquisadores do período de observação. Os resultados demonstraram elementos comuns extraídos das observações, do discurso dos trabalhadores e da avaliação documental. A pesquisa foi acompanhada quinzenalmente por supervisores sêniores com formação em ergonomia da atividade e em psicodinâmica do trabalho.

A ergonomia da atividade foi utilizada como abordagem metodológica de análise do trabalho voltado para a compreensão abrangente da atividade e de seus determinantes no conteúdo do trabalho. Como referencial teórico para a compreensão da vivência no trabalho e suas repercussões sobre a saúde mental dos sujeitos de pesquisa, foram utilizados os conceitos da PDT, cuja principal contribuição é compreender como a pessoa vive aquilo que faz.

Esse estudo foi desenvolvido como parte de um projeto abrangente envolvendo a identificação do perfil populacional e dos fatores de risco relacionados ao trabalho dos motoristas de ambulância do hospital e foi aprovado pela Comissão de Ética para Análise de Projetos de Pesquisa do Hospital das Clínicas da Faculdade de Medicina da Universidade de São Paulo.

\section{Resultados}

Com a análise documental, observações, entrevistas individuais e em grupo, os pesquisadores puderam identificar e compreenderas modificações ocorridas no trabalho dos motoristas de ambulância com a reestruturação organizacional de 2012. Até então, cada instituto possuía sua própria equipe de motoristas e as solicitações eram realizadas diretamente por meio do contato entre a equipede enfermagem e os motoristas. Logo, os motoristas possuíam autonomia para organizar seu trabalho conforme a demanda do instituto ao qual faziam parte e recebiam facilmente informações pertinentes às particularidades do transporte dos pacientes envolvidos.

\section{Conteúdo do trabalho real dos motoristas de ambulância}

A reestruturação do setor de transportes criou um intermediário entre a equipe de enfermagem e os motoristas de ambulância, denominado plantão regulador. Esse setor passou a ser responsável pelo recebimento do chamado da equipe de enfermagem, pela definição da prioridade de atendimento, do horário para o transporte e pela obtenção de informações referentes às condições clínicas do paciente. $\mathrm{O}$ plantão regulador transfere a informação para o líder de plantão que define qual tipo de ambulância é necessária e qual motorista responderá à solicitação. Assim, a sequência das principais tarefas realizadas pelos motoristas de ambulância pode ser representada pela Figura 1.

Como apresentado no fluxograma da Figura 1, após a reestruturação organizacional, a equipe de enfermagem não realiza contato direto com os motoristas no momento da solicitação para que um paciente seja transportado. O líder recebe as demandas do plantão regulador e aloca os motoristas para cada demanda, conforme a disponibilidade de pessoal. Somente em caso de urgências, os institutos possuem a liberdade de solicitar o transporte diretamente para o setor de transportes, que depois passará a informação para o plantão regulador.

Os motoristas têm autonomia para escolher a melhor rota para chegar ao lugar de acordo com horário do dia, o que eles aprendem pela experiência. Quando recebem um chamado, eles têm cinco minutos para chegar ao instituto onde o paciente está. Neste trajeto, geralmente enfrentam imprevistos como trânsito, obstruções de pista, acidentes ou clima, que afetam o tempo de 


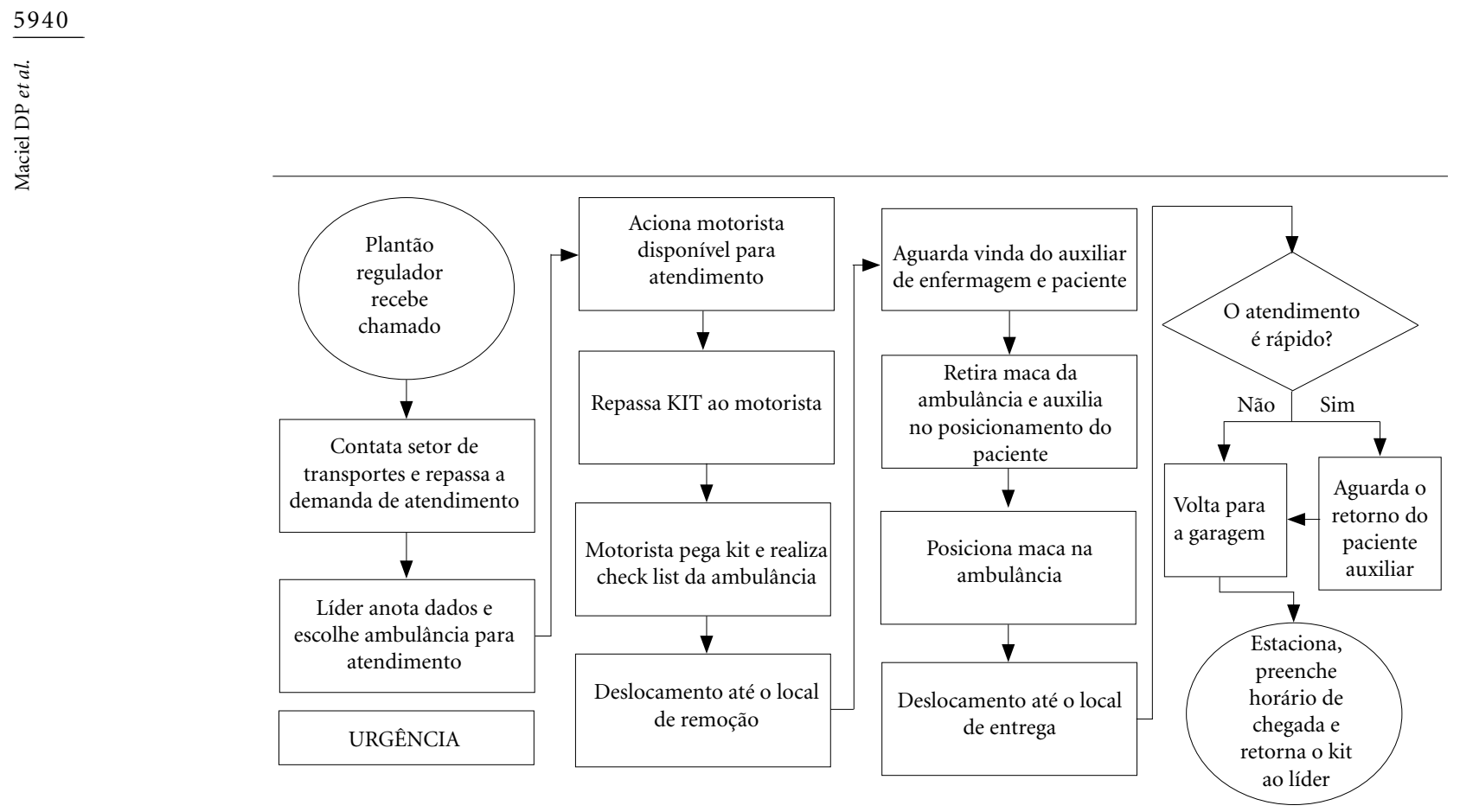

Figura 1. Descrição do conteúdo de trabalho dos motoristas e líderes depois da centralização do setor de transporte.

Fonte: Elaborado pelos autores.

deslocamento. Quando chegam a um instituto para buscar um paciente, eles precisam estacionar a ambulância e alguns institutos possuem vagas específicas para ambulância, outros não. Nestes últimos casos, os motoristas precisam procurar um local adequado ou parar a ambulância em local proibido, assumindo o risco de serem multados. Após estacionar a ambulância, eles aguardam o paciente.

Quando o paciente chega, o motorista remove a maca da ambulância para acomodá-lo. Nesse momento, diferentes situações podem acontecer: 1) paciente consegue subir na maca com pouca ou nenhuma supervisão; 2) paciente é acamado e a equipe de enfermagem e o motorista precisam ajudar a acomodá-lo na maca; 3) paciente é acamado em maca específica e não pode ser acomodado na maca da ambulância.

No caso específico do item 3 , em tese, os motoristas deveriam conhecer a situação com antecedência, para sair com a ambulância já sem a maca. Quando eles não conhecem a situação antecipadamente, eles deixam a maca da ambulância no instituto onde buscaram o paciente e precisam retornar ao local posteriormente para buscá-la (caso contrário, a ambulância torna-se disfuncional).

Motoristas então requisitam os documentos do chamado para anotar o ponto de saída, destino, hora da saída, quilometragem, tempo de espera, e coloca o paciente na maca dentro da ambulância. Esta atividade é de responsabilidade do motorista, bem como o fechamento da porta. Apenas em situações adversas (obesidade, condições severas, ajustes especiais na maca), a equipe de enfermagem, a equipe de segurança ou outros profissionais são requisitados para ajustar o paciente e a maca na ambulância. Finalmente, o motorista está pronto para levar o paciente ao local de destino.

Quando chegam ao destino, é esperado que uma equipe de enfermagem estivesse aguardando o paciente com outra maca para transportá-lo. Então, a tarefa prescrita seria passar o paciente da maca da ambulância para a maca do instituto e retornar à garagem. Novamente, outras situações imprevistas podem acontecer: 1) não há maca disponível no momento e o profissional de enfermagem leva o paciente para dentro do instituto usando a da ambulância e os motoristas precisam esperar o retorno desta maca; 2) há atrasos na liberação ou autorização de entrada de pacientes no instituto de destino; 3 ) motoristas aguardam sozinhos com os pacientes enquanto o profissional de enfermagem busca outra maca, cadeira de rodas ou documentos dentro do instituto; 4) outros profissionais, além do motorista e enfermeiro, são requisitados para a remoção do paciente em situações adversas.

Ao transportar o paciente ao destino e ao retornar à garagem, os motoristas enfrentam as 
mesmas imprevisibilidades no trânsito citadas anteriormente. Por fim, de volta à garagem, eles preenchem um formulário com o atendimento do chamado, incluindo as situações não previstas que ocorrerame aguardam um próximo chamado na sala de espera, dentro da ambulância ou na sala de convivência.

Dessa maneira, a duração de suas atividades não considera o conteúdo real do trabalho. O trabalho prescrito do motorista de ambulância contempla apenas a tarefa de dirigir o veículo, enquanto o trabalho real inclui também o cuidado do paciente e a relação com outros profissionais, sobretudo os da enfermagem.Entre as tarefas, os motoristas são responsáveis por acomodar os pacientes nas macas, prestando atenção a situações adversas ou delicadas, também fazem companhia aos pacientes enquanto o profissional de enfermagem lida com questões burocráticas dentro dos institutos.

\section{Indicadores de avaliação do trabalho dos motoristas}

O trabalho prescrito dos motoristas é dividido em três partes: (1) dirigir a ambulância da garagem ao instituto no qual o paciente se encontra; (2) transportar o paciente de um instituto a outro e; (3) retornar a ambulância à garagem. Este trabalho é avaliado essencialmente pelo indicador de tempo destas três etapas, cuja meta é de cinco minutos por percurso. Esse indicador foi definido durante o processo de reestruturação organizacional, sem o envolvimento direto dos motoristas. Trata-se de uma média que desconsidera quaisquer intercorrências e a variabilidade das demandas devido às condições dos pacientes, à dinâmica dos institutos e demais dificuldades fora do controle dos motoristas.

Segundo os motoristas, os conflitos com a enfermagem ocorrem em virtude da falta de alinhamento entre as necessidades do transporte e as informações passadas aos motoristas. Além disso, outro foco de conflito está na retenção da maca da ambulância no instituto, pois a ambulância fica disfuncional e impacta diretamente no indicador de tempo.

Assim, embora o principal indicador no trabalho dos motoristas seja o tempo, eles não têm controle sobre esta variável, já que há muitos imprevistos durante o transporte. Além do mais, os motoristas de ambulância não participaram da definição do indicador, logo, o tempo real para completar cada etapa do transporte não foi considerado na definição da meta.

\section{Sentido do trabalho}

O trabalho dos motoristas envolve um componente emocional em relação aos pacientes. Eles criam vínculos com os pacientes e fazem de tudo para atender às necessidades e preferências de cada um, com o máximo de conforto possível. Muitas vezes, precisam ficar com os pacientes enquanto a equipe de enfermagem cuida da liberação e entrada no instituto. Assim, apesar do trabalho prescrito dos motoristas ser o deslocamento entre institutos, há contato direto com os pacientes. Os motoristas relatam se sentirem responsáveis pelos pacientes e se preocupam em garantir a segurança deles.

Os trabalhadores também verbalizaram a sua preocupação no cuidado com os pacientes, que aumenta quando transportam crianças ou idosos, que se estende aos familiares. Alguns motoristas manifestaram que se sentem diminuídos em relação à equipe médica e de enfermagem, pois esses profissionais não reconhecem sua participação no cuidado e os tratam com menosprezo. Eles reportaram um sentimento de exclusão e falta de reconhecimento de que também poderiam ser considerados como profissionais da saúde, sentimentos esses que conflitam com o sentido que os motoristas de ambulância atribuem ao seu trabalho.

\section{Discussão}

O presente estudo revelou os impactos na saúde mental dos trabalhadores de ambulância de um grande hospital público submetidos a uma reestruturação organizacional, baseada em conceitos tayloristas-fordistas, que desconsiderou o conteúdo do trabalho real e o sentido do trabalho. O resultado desse estudo está em harmonia com os resultados deFløviket $\mathrm{al}^{9}$, Falkenberg et al. ${ }^{7}$ e Bamberger et al. ${ }^{10}$, que revelaram o impacto negativo de mudanças organizacionais sobre a saúde mental dos trabalhadores de serviços de saúde. Outros fatores, além de demanda e controle sobre o trabalho, estariam envolvidos na gênese da deterioração da saúde mental desses trabalhadores. Nesse contexto, a precarização do trabalho pela perda do valor do trabalho, das relações de trabalho e da identidade profissional surgem como possíveis explicações ${ }^{3,4,5}$. Ingelsrud ${ }^{4}$ e Fløvik et al. ${ }^{9}$ procuraram identificar os fatores do ambiente de trabalho associados às repercussões negativas sobre a saúde dos trabalhadores. Todavia, ambos os trabalhos demonstraram que o modelo utilizado não se revelou útil para com- 
preender a relação dos constrangimentos do trabalho com o surgimento dos sintomas psíquicos.

A reestruturação organizacional do trabalho dos motoristas de ambulância foi baseada em uma racionalidade teleológica, que prioriza a concentração da produção para ganhos de produtividade e qualidade ${ }^{19}$. Segundo essa lógica, os recursos chamados ambulâncias deveriam ser melhor utilizados por todos os institutos, reduzindo a ocorrência de equipamentos ociosos. Desta maneira, centralizar os recursos (as ambulâncias) em uma gestão única traria ganhos em custos e eficiência para todo hospital, além de uma divisão do uso de acordo com as demandas dos pacientes e dos institutos.

Ainda segundo essemesmo racional, os motoristas de ambulância são responsáveis apenas por dirigir ambulâncias no menor tempo possível. Assim, o único indicador que mede, acompanha e avalia a atividade de dirigir ambulâncias seria o tempo. Com isso, a única parte do trabalho dos motoristas reconhecido pela organização e, consequentemente, visível por esta, está baseada no indicador temporal herdado da lógica industrial que desconsidera o trabalho real desses profissionais, em que a relação com os outros, sobretudo o cuidado com os pacientes, é fundamental. Decorrem, então, dois conflitos: o fato de os motoristas não terem o controle sobre o único indicador pelo qual são avaliados e a simplificação de um trabalho que vai além da condução de um veículo em um intervalo de tempo de cinco minutos.

O primeiro conflito resulta de duas questões. Primeiramente, há variabilidades no trânsito, nas condições climáticas e na disponibilidade de vagas para estacionamento. Além disso, há imprevistos com as outras pessoas envolvidas no trajeto, como pacientes que requerem maior tempo para sua acomodação, equipe de enfermagem que podem atrasar e questões burocráticas a serem resolvidas. Assim, o tempo total para transporte do paciente de um local para o outro não representa o trabalho real dos motoristas e está longe de ser gerenciável por eles, já que existem outros fatores também podem influenciar neste indicador de forma negativa.

Há muita controvérsia acerca da avaliação do trabalho. Os aportes da PDT para este debate são fundamentais. Segundo Dejours ${ }^{18}$, não é possível mensurar o trabalho porque o trabalho se situa na experiência subjetiva do indivíduo. Para este autor, diante da impossibilidade de mensurar o trabalho, é comum traduzi-lo em uma medida de tempo de atividade e entender - erroneamente - que por meio desta mensuração o trabalho será avaliado. É importante ressaltar que a medição de tempo explica a duração da atividade e não sua intensidade, esforço, qualidade e o real conteúdo do trabalho ${ }^{18}$, além de não considerar os valores imateriais do serviço, como confiança, cooperação e pertinência ${ }^{20}$. Ou seja, a escolha pela gestão de tempo coloca em evidência a falta de reconhecimento do trabalho real do motorista de ambulância, especialmente no que diz respeito ao cuidado do paciente, o que leva ao segundo conflito: a simplificação do trabalho do motorista a um mero executor do transporte.

A mudança organizacional destinada a otimizar o uso das ambulâncias desconsidera o sujeito (motorista de ambulância) e o trabalho real (transporte dos pacientes) e considera que os motoristas são meros "executores" da atividade de conduzi-las e os coloca como parte do recurso material chamado "ambulância", desconsiderando o sujeito e o trabalho real. Ou seja, os motoristas são tratados como "recursos" que devem ser otimizados. A análise dos resultados demonstra que o trabalho real dos motoristas de ambulância é invisível para a organização, pois várias atividades não são reconhecidas pelos demais atores do processo tampouco consideradas na decisão pela reestruturação, como, por exemplo, os cuidados com o paciente, não previstos no trabalho prescrito.

Sznelwar ${ }^{21}$ argumenta que todos os profissionais que de alguma maneira se envolvem com o paciente também se envolvem com o cuidado. Todo trabalhador do hospital está de alguma maneira envolvido na atividade-fim da organização, que é o cuidado do paciente. Molinier ${ }^{23}$ afirma que uma parte importante do trabalho dos motoristas de ambulância é a participação no cuidado com os pacientes, que envolve a mobilização de sentimento de compaixão, orientado para atenção com o sofrimento do outro. Ainda, de acordo com Sznelwar ${ }^{21}$, o trabalho de cuidar acontece efetivamente quando há espaço para compaixão e para criação devínculo, que para os motoristas, sãoconsiderados como elementos de sentido do trabalho. Entretanto, quando a gestão de tempo é usada como único indicador para avaliar o trabalho dos motoristas de ambulância, não se pode mais reconhecer seu papel efetivo no cuidado do paciente, levando à precarização do trabalho.

Em PDT, defende-se a tese da centralidade do trabalho como oportunidade para constituição do sujeito ${ }^{22}$, como base para construção de saúde, para o desenvolvimento profissional e realização pessoal ${ }^{18,23}$. O trabalho desenvolve a inteligência e permite o crescimento subjetivo, mobilizando a personalidade por inteiro ${ }^{18,23}$ e possibilitando 
que o sujeito encontre seu lugar na sociedade ${ }^{21}$. O sujeito percebe, então, o ambiente de trabalho como um prolongamento de si próprio e este ambiente é o lugar de criação de sua subjetividade ${ }^{23}$. Nesta construção de identidade, dois pilares são fundamentais: o pertencimento, que coloca o sujeito em um grupo social, e a singularidade, que distingue o sujeito de seus pares pelas suas características únicas ${ }^{23}$.

No entanto, após a reestruturação organizacional, estes pilares da construção de identidade dos motoristas de ambulâncias foram rompidos, assim como os laços de confiança e cooperação criados anteriormente com as equipes específicas de cada instituto. Por um lado, eles perderam algumas características prévias, como o pertencimento ao instituto, a uma equipe de profissionais de saúde específica, que os conheciam pelo nome e com os quais tinham contato direto para organizar as demandas. Por outro lado, também perderam a singularidade, pois foram tratados como parte do recurso "ambulância”, e assim poderiam ser divididos, otimizados e distribuídos com base em tempo e disponibilidade. Molinier ${ }^{23}$ afirma que o ser humano não deve se tornar uma máquina, o ser humano deve humanizar a máquina. Com a centralização do setor de transportes em busca de produtividade, os sujeitos foram tratados com os mesmos critérios de gestão do recurso "ambulâncias". Ou seja, os motoristas deixaram de ser vistos como sujeitos para serem considerados "coisas", caracterizando, literalmente, uma reificação do trabalho desses profissionais e ferindo então o sentido do trabalho e a construção de identidade.

Como visto, a mudança organizacional acarretou uma alteração no contexto de trabalho dos motoristas de ambulância que resultou em perda de identidade profissional e falta de reconhecimento pela organização daquilo que os motoristas consideram como valor e sentido de seu trabalho. Ao analisar as implicações de mudanças organizacionais sobre a segurança e saúde de trabalhadores, Guida et al. ${ }^{8}$ constataram que a ausência de reconhecimento produz consequências sobre a saúde física e mental dos trabalhadores. Essa alteração no contexto de trabalho, associada à utilização equivocada do indicador tempo, que desconsidera o conteúdo do trabalho real desses trabalhadores, emergiu da análise de campo como um dos elementos primários na gênese dos conflitos na interação dos motoristas com a equipe de enfermagem.

Mudanças organizacionais que adotam práticas voltadas à lógica instrumental de padroniza- ção e protocolização de forma pragmática revelam o confronto entre o trabalho real e as demandas dos sujeitos por sentido e reconhecimento no trabalho. Segundo Azevedo et al. ${ }^{24}$, hospitais públicos brasileiros buscaram a instrumentalização dos processos e a adoção de padrões de qualidade e segurança na produção do cuidado assistencial. Entretanto, os conflitos surgem quando essa racionalidade instrumental é confrontada com o trabalho real dos sujeitos e coletivos de trabalhadores que constroem sua prática em relações intersubjetivas, que envolvem reconhecimento e experiências coletivas que constituem o sentido e valor da profissão ${ }^{24}$.

Portanto, a reestruturação organizacional efetuada pela gerência do hospital desconsiderou o trabalho real e o sentido do trabalho dos motoristas de ambulância, reduzindo-o à ação de dirigir, "coisificando" e esvaziando o valor do trabalho desses profissionais. Esse contexto de precarização do trabalho manifestou-se por meio de conflitos com a equipe de enfermagem e se materializou em queixas de irritabilidade e agressividade dos motoristas. É importante que os profissionais envolvidos na atenção à saúde dos trabalhadores busquem estratégias de compreensão do trabalho real diante de demandas que envolvam a saúde mental dos trabalhadores. O impacto negativo na saúde mental dos trabalhadores sofre influência dos elementos da organização do trabalho, que podem ser elucidadas por estratégias mais compreensivas de avaliação do trabalho. Assim, a ergonomia da atividade, que dialoga com conceitos da subjetividade do trabalhador trazidos pela psicodinâmica do trabalho, pode cumprir esse papel.

\section{Colaboradores}

LI Sznelwar fez supervisão e acompanhamento durante a pesquisa de campo, participou da elaboração da metodologia e conclusões. No artigo atuou na revisão geral. E Costa Sá se responsabilizou pela interlocução que possibilitou a pesquisa na instituição, supervisão na coleta de dados e análise. No artigo, revisão e complementação da escrita final. DP Maciel, pesquisadora de campo, atuou na coleta de dados, análise e interpretação dos resultados. No artigo participou da escrita do manuscrito e suas revisões. R Giannini contribuiu na elaboração do artigo, escrita e revisões escritas. 


\section{Referências}

1. Barnett WP, Carroll GR. Modeling internal organizational change. Annual Review of Sociology 1995; 21(1):217-236.

2. Mintzberg H, Westley F. Cycles of Organizational Change. Strategic Manag J 1992; 13(S2):39-59.

3. Grønstad A, Kjekshus LE, Tjerbo T, Bernstrøm VH. Organizational change and the risk of sickness absence: a longitudinal multilevel analysis of organizational unit-level change in hospitals. BMC Health Serv Res 2019; 19(1):895.

4. Ingelsrud MH. Reorganization increases long-term sickness absence at all levels of hospital staff: panel data analysis of employees of Norwegian public hospitals. BMC Health Serv Res 2014; (14):411.

5. Bernstrøm VH, Kjekshus LE. Effect of organisational change type and frequency on long-term sickness absence in hospitals. J Nurs Manag 2015; 23(6):813-822.

6. Jensen JH, Flachs EM, Skakon J, Rod NH, Bonde JP. Dual impact of organisational change on subsequent exit from work unit and sickness absence: a longitudinal study among public healthcare employees. Occup Environ Med 2018; 75(7):479-485.

7. Falkenberg H, Fransson EI, Westerlund H, Head JA. Short- and long-term effects of major organisational change on minor psychiatric disorder and self-rated health: results from the Whitehall II study. Occup Environ Med 2013; 70(10):688-696.

8. Guida HFS, Brito J, Alvarez D. Gestão do trabalho, saúde e segurança dos trabalhadores de termelétricas: um olhar sob o ponto de vista da atividade. Cien Saude Coletiva 2013; 18(11).

9. Fløvik L, Knardahl S, Christensen JO.Organizational change and employee mental health: A prospective multilevel study of the associations between organizational changes and clinically relevant mental distress. Scand J Work Environ Health 2019; 45(2):134-145.

10. Bamberger SG, Vinding AL, Larsen A, Nielsen P, Fonager K, Nielsen RN, Ryom P, Omland Ø. Impact of organisational change on mental health: a systematic review. Occup Environ Med 2012; 69(8):592-598.

11. Bartram T, Stanton P, Bamber GJ, Leggat SG, Ballardie R, Gough R. Engaging Professionals in Sustainable Workplace Innovation: Medical Doctors and Institutional Work. British J Manage 2020; 31(1):42-55.

12. Alonso JM, Clifton J, Díaz-Fuentes D. The impact of New Public Management on efficiency: An analysis of Madrid's hospitals. Health Policy 2015; 119(3):333340.

13. Costa NR, Ribeiro JM, Silva, PLB. Reforma do Estado e mudança organizacional: um estudo de hospitais públicos. Cien Saude Colet 2000; 5(2):427-442.
14. Grumbach K, Knox M, Huang B, Hammer H, Kivlahan C, Willard-Grace R. A longitudinal study of trends in burnout during primary care transformation. Ann Fam Med 2019; 17(Supl. 1):S9-S16.

15. Smollan RK, Morrison RL. Supporting Others Through Stressful Organizational Change. J Applied Behav Sci 2019; 55(3):327-351.

16. Wisner A. Por dentro do trabalho: ergonomia: método \& técnica. São Paulo: FTD/Oboré; 1987.

17. Guérin F, Lavill, A, Daniellou F, Duraffourg J, Kerguelen A. Compreender o trabalho para transformá-lo: a prática da ergonomia. São Paulo: Blucher: Fundação Vanzolini; 2001.

18. Dejours C. Trabalho Vivo, tomo II, Trabalho e Emancipação. Brasília: Paralelo 15; 2012.

19. Zarifian P. Mutação dos sistemas produtivos e competências profissionais: a produção industrial do serviço. [A. do livro] M. S. Salerno. Relação de serviço. Produção e avaliação. São Paulo: Editora SENAC São Paulo; 2001.

20. Hubault F. Corps, activité, espace - nouvelles interpellations de l'économie dématérialisée. In: Hubault F, coordenador. Les espaces du travail; enjeux savoirs, pratiques - actes $d u$ séminaire Paris 1 . Toulouse: Editions Octarès; 2017. p. 3-12.

21. Sznelwar LI. Quando trabalhar é ser protagonista e o protagonismo no trabalho. São Paulo: Blucher; 2015.

22. Dejours C. Trabalho Vivo, tomo I, Sexualidade e trabalho. Brasília: Paralelo 15; 2012.

23. Molinier P. O trabalho e a psique - uma introdução à psicodinâmica do trabalho. Brasília: Paralelo 15; 2013.

24. Azevedo CDS, Sá MDC, Cunha M, Matta GC, Miranda L, Grabois, V. Racionalização e Construção de Sentido na Gestão do Cuidado: uma experiência de mudança em um hospital do SUS. Cien Saude Colet 2017; 22(6):1991-2002.

Artigo apresentado em 21/05/2020

Aprovado em 22/07/2021

Versão final apresentada em 24/07/2021

Editores-chefes: Romeu Gomes, Antônio Augusto Moura da Silva 